\title{
Effect of size and toasting degree of oak chips used for winemaking on the ellagitannin content and on the acutissimin formation ${ }^{\text {is }}$
}

\author{
L. Le Grottaglie a, I. García-Estévez ${ }^{\text {b }}$, R. Romano a, N. Manzo a , J.C. Rivas-Gonzalo b, \\ C. Alcalde-Eon ${ }^{\mathrm{b}}$, M.T. Escribano-Bailón ${ }^{\mathrm{b}, *}$ \\ a University of Naples Federico II, Department of Chemical Sciences, Via Universitá, 100 Portici, 80055 Naples, NA, Italy \\ ${ }^{\mathrm{b}}$ Grupo de Investigación en Polifenoles (GIP), Unidad de Nutrición y Bromatología, Facultad de Farmacia, Universidad de Salamanca, Salamanca, Spain
}

\section{A R T I C L E I N F O}

\section{Article history:}

Received 2 December 2013

Received in revised form

30 June 2014

Accepted 15 October 2014

Available online 24 October 2014

\section{Keywords:}

C-glycosidic ellagitannin

Acutissimin

Oak chip

Toasting

$(+)$-catechin

\begin{abstract}
A B S T R A C T
The effect of size ( 2 and $8 \mathrm{~mm}$ ) and toasting degree (light, medium and high) of oak chips on the Cglycosidic ellagitannins composition of model wine solutions has been studied by HPLC-ESI-MS-MS. Furthermore, the effect of the presence of $(+)$-catechin $(50 \mathrm{mg} / \mathrm{L}$ and $200 \mathrm{mg} / \mathrm{L})$ in the solution was assessed. Respecting toasting, the levels of ellagitannins were higher and reached earlier when lighttoasted chips were used. Regarding chip size, the highest ellagitannin contents were found in the solutions in contact with the smallest oak chips. Nevertheless, the size of oak chips can be crucial depending on the toasting degree: high temperatures or long times of toasting can provoke the ellagitannin degradation from the whole chip if its size is too small. Acutissimins A and B were detected in the solutions containing $(+)$-catechin. Unlike the levels of acutissimins, the ellagitannin composition was not affected by the concentration of $(+)$-catechin in the solutions.
\end{abstract}

(c) 2014 Elsevier Ltd. All rights reserved.

\section{Introduction}

Wine aging using oak barrels is a traditional practice to which quality wines are subjected. Nowadays, wine aging in stainless steel tanks with oak chips is an alternative practice to the use of oak barrels since the storage and handling of the oak barrels make traditional aging expensive. The use of oak chips can increase the competitiveness of wineries as it reduces the costs of production.

The European Union (EU) authorized the use of wood chips by the EC Regulations 2165/2005 "concerning the use of pieces of oak wood in winemaking" and regulated the designation and presentation of the wine treated with pieces of oak wood ((CE) No 1507/ 2006).

During barrel aging, wine undergoes a series of transformations leading to important changes in aroma, color, taste, and astringency (Glabasnia \& Hofmann, 2006; Puech, Feuillat, \& Mosedale, 1999). This is due in part to a progressive extraction of wood compounds such as aldehydes, phenolic acids and C-glycosidic ellagitannins (Fernández de Simón, Sanz, Cadahía, Poveda, \& Broto, 2006). Among the C-glycosidic ellagitannins, castalagin and vescalagin are the two monomeric ellagitannins that largely predominate in oak

\footnotetext{
Selected paper presented at In Vino 2013- Reims, France from 3 to 5 July 2013.

* Corresponding author.

E-mail address: escriban@usal.es (M.T. Escribano-Bailón).
}

wood representing $40 \%-60 \%$ of the ellagitannins, although lyxose/ xylose derivatives (grandinin and roburin E) are also present in smaller percentages (Hervé du Penhoat et al., 1991; Jourdes, Lefeuvre \& Quideau, 2009; Masson, Moutounet, \& Puech, 1995). The structure of ellagitannins enables these compounds to take part in oxidation reactions, acting as consumers of oxygen and favoring, among other reactions, the transformation of ethanol into acetaldehyde (Vivas \& Glories, 1996), which can be involved in polymerization reactions between flavanols and between flavanols and anthocyanins (Francia-Aricha, Guerra, Rivas-Gonzalo, \& Santos-Buelga, 1997; Timberlake \& Bridle, 1976; Vivas \& Glories, 1996), affecting wine astringency and color, respectively. Furthermore, ellagitannins could directly affect wine color (Chassaing et al., 2010; Quideau et al., 2005) and also could contribute to increase the astringency and the bitterness of wine aged in oak barrels or with oak chips due to their ability to precipitate salivary proteins (Glabasnia \& Hofmann, 2006).

Moreover, ellagitannins can react directly with other wine constituents. In particular, vescalagin is able to react with (epi) catechins via $\mathrm{C}-\mathrm{C}$ linkage between the carbon- 1 atom of the vescalagin moiety and either carbon- 8 or -6 of the A ring of the (epi) catechin to form acutissimin A or B, respectively (Quideau et al., 2005). These compounds have been reported to possess interesting biological properties as antitumoral (Quideau et al. 2005). 
The ellagitannins contents and their proportions in oak wood are affected by several factors among which toasting has been pointed out as one of the most important (Fernández de Simón, Cadahía, Del Álamo, \& Nevares, 2010). The influence of toasting on the extraction of phenolics from the oak wood (Cadahía, Varea, Muñoz, Fernández de Simón, \& García -Vallejo, 2001; Doussot, De Jesso, Quideau, \& Pardon, 2002; Fernández de Simón, Hernández, Cadahía, Dueñas, \& Estrella, 2003; Hale, McCafferty, Larmie, Newton, \& Swan, 1999) is well established in literature. Some of the works focused on the phenolic composition also studied the ellagitannin composition depending on the toasting degree, but they only determined the ellagitannin levels by the quantification of ellagic acid released during acidic hydrolysis (Chira \& Teissedre, 2013).

There are few studies focusing on the importance of the size of the pieces of oak wood. Moreover, they are devoted to the volatile composition (Fernández de Simón, Cadahía, Del Álamo \& Nevares, 2010). To our knowledge there are no studies that have monitored the individual extraction of ellagitannins depending on the size of oak chips and on their toasting levels. Taking into account the differences of reactivity and activity between the different ellagitannins (Jourdes, et al., 2009, Quideau et al., 2005), it is important to know the effect of toasting on them.

On the other hand, the formation of flavano-ellagitannin has been studied both in model solution (Quideau et al., 2005) and in wine (Jourdes, Michel, Saucier, Quideau, \& Teissedre, 2011), but there are no studies that try to correlate the formation of these compounds with the toasting degree of the oak or with the flavanol concentrations. This could be important considering the properties described for these derivative ellagitannins (Quideau et al., 2005).

Thus, the aim of this work was to study how the size ( 2 and $8 \mathrm{~mm}$ ) and the toasting degree (light, medium and high) of oak chips affect the composition of individual C-glycosidic ellagitannins in model wine solutions. Furthermore, the effect of the presence of $(+)$-catechin $(50 \mathrm{mg} / \mathrm{L}$ and $200 \mathrm{mg} / \mathrm{L}$ ) in the model solutions on the ellagitannins extraction and on the acutissimin A and B formation was also investigated.

\section{Materials and methods}

\subsection{Chemicals}

Vescalagin was isolated from commercial chestnut tannin provided by Laffort (Laffort oenologie, Bordeaux, France). Castalagin, roburin E and grandinin were isolated from non-toasted Quercus petraea oak chips (see Section 2.4 for further details). Acutissimin A and B were obtained by hemisynthesis from vescalagin as it is described by Quideau and co-workers (Quideau et al., 2005) and purified by semi-preparative HPLC.

$(+)$-Catechin and (-)-gallocatechin were purchased from Sigma-Aldrich (St. Louis, MO, USA). All solvents used were of analytical grade and were purchased from Prolabo (BHD) VWR International (Briare, France). Ultrapure water was obtained from a Direct-Q water purification system equipped with a Millipak 40 $(0.22 \mu \mathrm{m})$ filter unit (Millipore, Billerica, MA, USA).

\subsection{Oak chips}

The oak chips added to model wine solutions were provided from AEB Group (Brescia, Italy) and were obtained from naturally seasoned (24 months) $Q$. petraea oak from central and eastern France. Two different sizes (Length $\times$ width $\times$ height $=4 \times 2 \times 1 \mathrm{~mm}$ $(2 \mathrm{~mm})$, and $\mathrm{L} \times \mathrm{W} \times \mathrm{h}=4 \times 8 \times 1 \mathrm{~mm}(8 \mathrm{~mm}))$ and three different levels of toasting for each size (light, L; medium, M; and high, H) were used.

\subsection{Preparation of the model wine solutions}

Model wine solutions (MWS) consisted of $12 \mathrm{~mL} / 100 \mathrm{~mL}$ ethanol in ultrapure water, $3.8 \mathrm{~g} / \mathrm{L}$ of tartaric acid and $0.6 \mathrm{~g} / \mathrm{L}$ of potassium chloride (adjusted at $\mathrm{pH} 3.3$ using $\mathrm{NaOH} 1 \mathrm{M}$ ). Oak chips $(4 \mathrm{~g} / \mathrm{L})$ were added in the model wine solutions containing different concentrations of $(+)$-catechin: $0 \mathrm{mg} / \mathrm{L}$ (reference samples), $50 \mathrm{mg} / \mathrm{L}$ and $200 \mathrm{mg} / \mathrm{L}$. Two sizes of oak chips were used in the study (2 mm and $8 \mathrm{~mm}$ ), and different toasting level for each size (light, L; medium, M; and high, $\mathrm{H}$ ) were used. In total, eighteen different model wine solutions were prepared (see Table 1 for code descriptions). The sampling started the day after the oak chips (and the catechin in non-reference samples) were added (day 1 ) and it was prolonged for 35 days. Samples were taken weekly. Each sample was analyzed in triplicate by HPLC-ESI-MS/MS-multiple reaction monitoring.

\subsection{Purification of the ellagitannins}

For the extraction of vescalagin, $3 \mathrm{~g}$ of the commercial chestnut tannin was dissolved in $150 \mathrm{~mL}$ of acidified water $(\mathrm{AcOH} 2.5 \mathrm{~mL}$ in $100 \mathrm{~mL}$ of ultrapure water, $\mathrm{pH}=3.36$ ). The solution was cleaned three times with diethyl ether and three times with ethyl acetate in order to remove other oak wood compounds that might interfere in further isolation steps. Traces of organic solvents were removed under vacuum and the extract was diluted in $750 \mathrm{~mL}$ of acidified water. Castalagin, grandinin and roburin $\mathrm{E}$ were extracted from oak chips following the procedure described by García-Estévez and co-workers (García-Es tevéz, Escribano-Bailón, Rivas-Gonzalo, \& Alcade-Eon, 2010). The purification of ellagitannins was performed using an Agilent Technologies 1260 Infinity LC Purification system (Agilent Technologies, Waldbronn, Germany) controlled by ChemStation software (Agilent Technologies, Waldbronn, Germany). The purification was performed using a $21.2 \mathrm{~mm} \times 150 \mathrm{~mm}, 5 \mu \mathrm{m}$ Agilent Prep C-18 column (Agilent Technologies, Waldbronn, Germany). Mobile phases were solvent A: acidified water (AcOH $2.5 \mathrm{~mL}$ in $100 \mathrm{~mL}$ of ultrapure water) and $\mathrm{B}$ : methanol. The following gradient was used: $(0-14 \mathrm{~min}, 0 \% \mathrm{~B}$; 14-22 min; 0-65\% B; 22-27 min, 65-0\% B). Detection was carried out at $250 \mathrm{~nm}, 280 \mathrm{~nm}$ and $360 \mathrm{~nm}$. The final purities of the isolated ellagitannins (higher than 95\%) were determined from the results of the HPLC-DAD-MS analyses (García-Estevéz, et al., 2010).

\subsection{Purification of acutissimin $A$ and $B$}

Purification of acutissimin A and B was performed using the same equipment, column, and mobile phases as ellagitannins. Nevertheless, the gradient used was different: $(0-10 \mathrm{~min}, 0 \% \mathrm{~B}$; 10-30 $\mathrm{min} ; 30 \% \mathrm{~B} ; 30-40 \mathrm{~min}, 60 \% \mathrm{~B} ; 40-45 \mathrm{~min}, 75 \% \mathrm{~B}$; $45-50 \mathrm{~min}, 0 \% \mathrm{~B})$. Detection was performed at $250 \mathrm{~nm}, 280 \mathrm{~nm}$ and $360 \mathrm{~nm}$. Final purity of each acutissimin was higher than $95 \%$.

\subsection{Quantification}

Vescalagin, castalagin, roburin E and grandinin were quantified by using the previously validated HPLC-ESI-MS/MS-multiple reaction monitoring method (García-Estevéz, et al., 2010; GarcíaEstevéz, Escribano-Bailón, Rivas-Gonzalo \& Alcalde-Eon, 2012). HPLC analyses were performed in a Hewlett-Packard 1100 series liquid chromatograph (Agilent Technologies, Waldbronn, Germany). MS detection was performed in an API 3200 Qtrap (Applied Biosystems, Darmstadt, Germany) equipped with an ESI source and a triple-quadrupole linear ion trap mass analyzer that was controlled by Analyst 5.1 software (Applied Biosystems, Darmstadt, Germany). Zero grade air served as nebulizer gas (344.7 kPa) and turbo gas for solvent drying $\left(400{ }^{\circ} \mathrm{C}, 413.7 \mathrm{kPa}\right)$. Nitrogen served as curtain (137.9 $\mathrm{kPa}$ ) and collision gas (high). Both quadrupoles were 
Table 1

Characteristics of the model solutions analyzed: code, (+)-catechin content (mg/L) and toasting degree of oak chips used.

\begin{tabular}{lcl}
\hline Sample code & $(+)$-catechin content $(\mathrm{mg} / \mathrm{L})$ & Oak chips toasting degree \\
\hline 0F2L & 0 & Ligh \\
0F2M & 0 & Medium \\
0F2H & 0 & High \\
50F2L & 50 & Ligh \\
50F2M & 50 & Medium \\
50F2H & 50 & High \\
200F2L & 200 & Ligh \\
200F2M & 200 & Medium \\
200F2H & 200 & High \\
0F8L & 0 & Ligh \\
0F8M & 0 & Medium \\
0F8H & 0 & High \\
50F8L & 50 & Ligh \\
50F8M & 50 & Medium \\
50F8H & 50 & High \\
200F8L & 200 & Ligh \\
200F8M & 200 & Medium \\
200F8H & 200 & High \\
\hline
\end{tabular}

set at unit resolution. The ion spray voltage was set at $-4500 \mathrm{~V}$ in the negative mode. Optimization of the conditions was carried out automatically by direct infusion of acutissimin A. Settings used were as follows: declustering potential (DP), $-100 \mathrm{~V}$; entrance potential (EP), $-10 \mathrm{~V}$; collision energy (CE), $-38 \mathrm{~V}$; collision cell exit potential (CXP), $-28 \mathrm{~V}$. Acutissimin $\mathrm{A}$ and acutissimin $\mathrm{B}$ were quantified by using a calibration curve built with data supplied by mass spectrometry using the signal obtained for the transition (each parent ion-daughter ion pair) $\mathrm{m} / \mathrm{z} 1215 / \mathrm{m} / \mathrm{z} 917$ corresponding to the acutissimin A, corrected with the signal obtained for the transition corresponding to the internal standard (-)-gallocatechin $(\mathrm{m} / \mathrm{z} 305 / \mathrm{m} / \mathrm{z} 249)$. This calibration curve was built in the concentration range between $1.5 \times 10^{-1} \mathrm{mg} / \mathrm{L}$ and $7.5 \mathrm{mg} / \mathrm{L}$ of accutissimin A $\left(R^{2}=0.9995\right)$. The linear model that correlated the ratio accutissimin signal/internal standard signal $(y)$ with the accutissimin concentration $(x)$ was as follows:

$y=0.0051 x+0.1 \times 10^{-4}$.

Detection (LOD) and quantification (LOQ) limits for acutissimin were calculated following the procedure described by GarcíaEstévez and co-workers (García-Estévezet al., 2012) for ellagitannins. LOQ was $0.02 \mathrm{mg} / \mathrm{L}$ and LOQ was $0.09 \mathrm{mg} / \mathrm{L}$.

\subsection{Statistical analysis}

Analysis of variance (ANOVA) was conducted using the software XLSTAT 2006.6 (Addinsoft, Paris, France). Differences were considered significant at $p<0.05$.

\section{Results}

\subsection{Influence of the size and toasting level of oak chips}

In the model wine solutions (MWS) that contained the smallest oak chips ( $2 \mathrm{~mm}$ ), the highest levels of ellagitannins were detected in that containing light-toasted chips (OF2L). In this case, the total concentration of C-glycosidic ellagitannins increased to reach maximum value of $41.76 \mathrm{mg} / \mathrm{L}$ after 7 days, and then ellagitannins content decreased over time to reach the value of $25.78 \mathrm{mg} / \mathrm{L}$ after 35 days. In samples that contained medium-toasted oak chips (OF2M), the maximum concentration of total ellagitannins ( $18.89 \mathrm{mg} / \mathrm{L}$ ) was reached after 21 days. After that, a decrease in the ellagitannin content was also observed. The lowest content of C- glycosidic ellagitannins was detected in MWS in contact with hightoasted oak chips $(0 \mathrm{~F} 2 \mathrm{H})$, and the maximum concentration in that sample $(1.92 \mathrm{mg} / \mathrm{L}$ ) was reached later (after 28 days) than in the other MWS studied (Fig. 1). In all samples, castalagin was the Cglycosidic ellagitannin most representative (Fig. 2) followed by vescalagin. Roburin E was determined in all samples representing the lowest percentages whereas grandinin was only detected in OF2L and OF2M samples although in higher percentages than roburin $\mathrm{E}$.

Regarding the MWS containing the largest oak chips $(8 \mathrm{~mm})$ it was observed that in those with light-toasted chips (OF8L) the total concentration of C-glycosidic ellagitannins did not increase regularly and two maximum contents $(29.64 \mathrm{mg} / \mathrm{L}$ after 7 days and of $30.16 \mathrm{mg} / \mathrm{L}$ after 35 days) were observed (Fig. 3). In samples 0F8M total ellagitannins content increased regularly up to 21 days reaching at this point the maximum concentration $(15.85 \mathrm{mg} / \mathrm{L})$. In the MWS with high-toasted oak chips $(\mathrm{OF} 8 \mathrm{H})$ the maximum concentration of $8.32 \mathrm{mg} / \mathrm{L}$ was detected after 28 days (Fig. 3). In the case of MWS with the largest oak chips (samples 0F8L, OF8M and OF8F) castalagin was also the most abundant ellagitannin (Fig. 4), followed by vescalagin. In this case both grandinin and roburin $\mathrm{E}$ were detected in all samples, the latter representing the lowest percentages.

\subsection{Influence of the presence of catechin}

In the samples containing $50 \mathrm{mg} / \mathrm{L}$ and $200 \mathrm{mg} / \mathrm{L}$ of (+)-catechin the contents and the evolution of ellagitannins were similar to those observed in the corresponding MWS without catechin, and no significant differences were found as a consequence of the presence of catechin in the media (data not shown). Nevertheless, in MWS containing (+)-catechin, the formation of flavanoellagitannins could be monitored. A gradual formation of acutissimins A (Table 2) and B (Table 3) was observed.

The highest amounts of acutissimin $A$ and $B$ were detected in the MWS containing $200 \mathrm{mg} / \mathrm{L}$ of (+)-catechin that were in contact with the light-toasted oak chips (samples 200F2L and 200F8L). In these samples, the highest concentration of acutissimin A (Table 2) was reached after 35 days and that of acutissimin B after 28 days (Table 3). In the MWS containing $50 \mathrm{mg} / \mathrm{L}$ of (+)-catechin, acutissimins A and B were also detected although in lower levels. The highest levels were also found in the samples with light-toasted oak chips (samples 50F2L and 50F8L) and were also reached after 35 days (see Tables 2 and 3). In relation to the MWS containing light-toasted oak chips, the MWS containing medium-toasted oak chips showed much lower contents of acutissimin A and B and

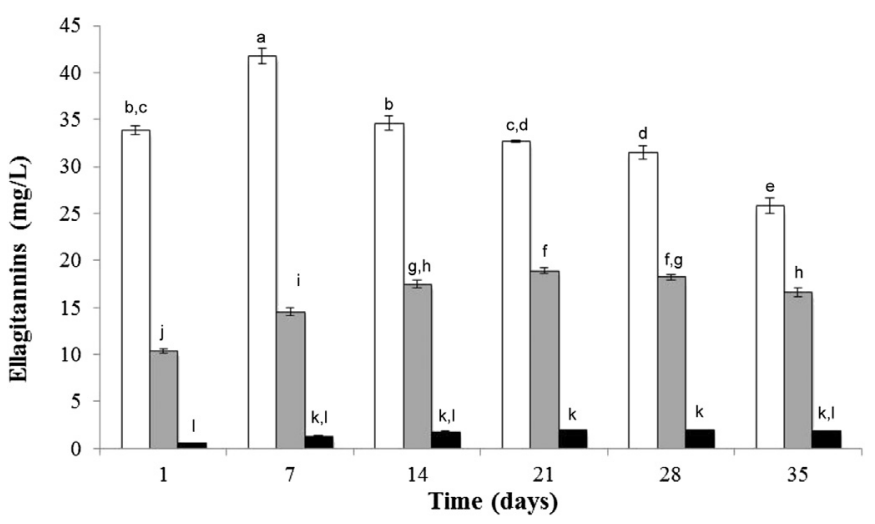

Fig. 1. Total content of ellagitannins $(\mathrm{mg} / \mathrm{L})$ in the model wine solutions in contact with $2 \mathrm{~mm}$ light (F2L, white), medium (F2M, gray) and high (F2H, black) toasted oak chips. Different lower case letters indicate significant differences for $p<0.05, n=3$. 

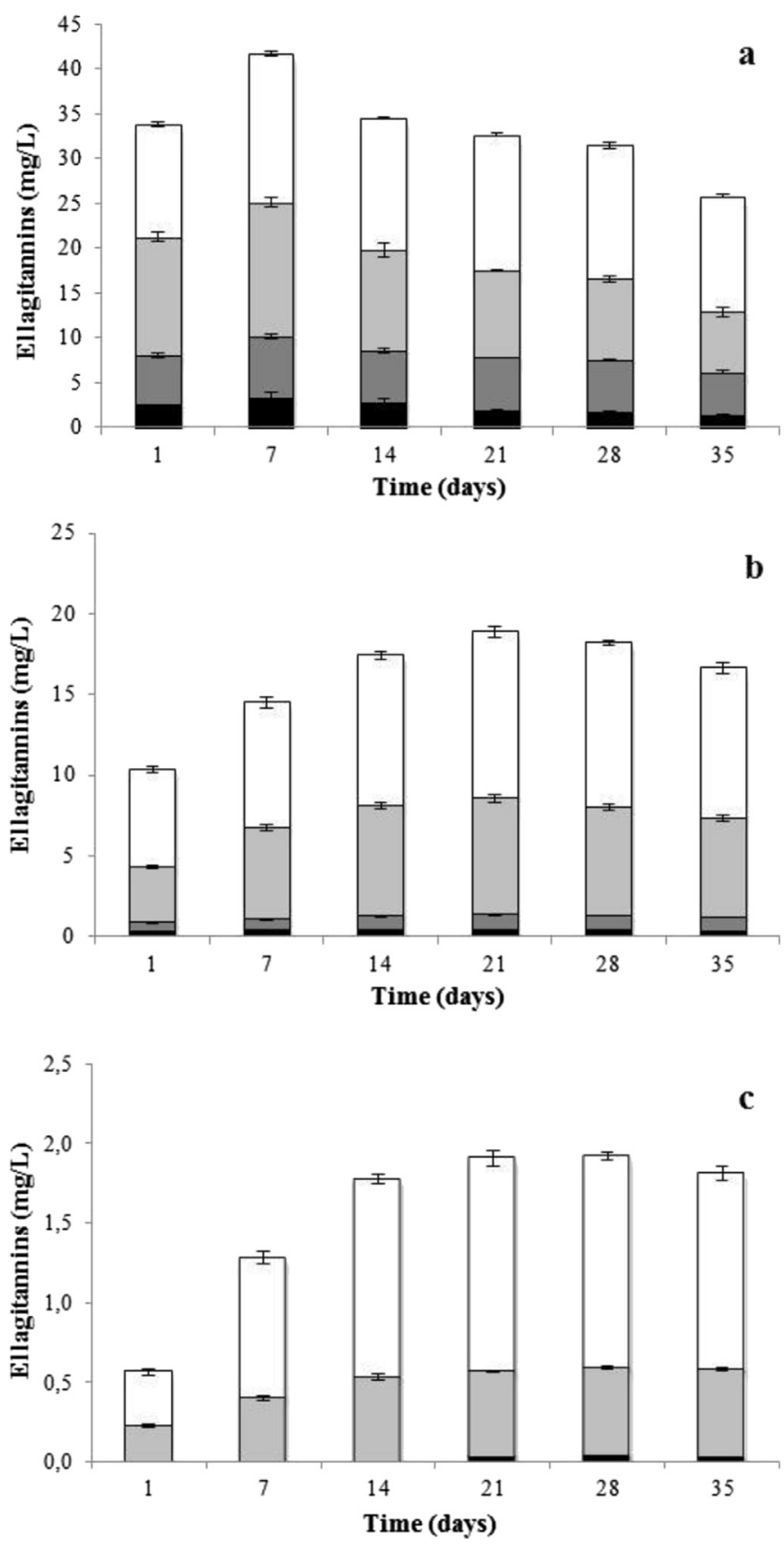

Fig. 2. Quantitative evaluation of individual C-glycosidic ellagitannins castalagin (white), vescalagin (light gray), grandinin (dark gray) and roburin E (black) in model wine solutions in contact with $2 \mathrm{~mm}$ light (a), medium (b) and high (c) toasted oak chips $(n=3)$.

among them, the contents were always lower in the MWS with the largest oak chips. In the MWS containing high-toasted oak chips, acutissimins A and B were not detected except for the set samples 200F8H (Tables 2 and 3).

\section{Discussion}

\subsection{Influence of the toasting level of the oak chips}

Significant differences in the total contents of C-glycosidic ellagitannins were found in both oak chip sizes considered $(2 \mathrm{~mm}$ and $8 \mathrm{~mm}$ ) for the toasting levels light (L), medium (M) and high (H) (Figs. 1 and 3). The highest contents of C-glycosidic

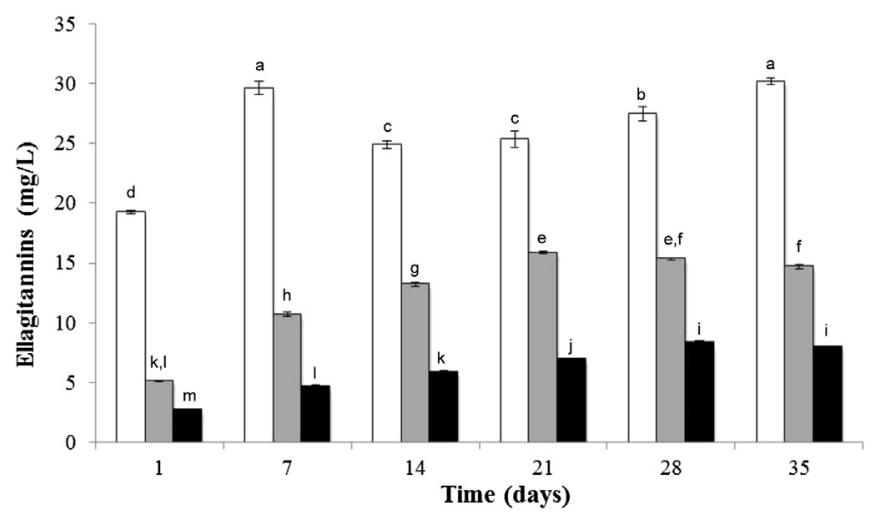

Fig. 3. Total content of ellagitannins $(\mathrm{mg} / \mathrm{L})$ in the model wine solutions in contact with $8 \mathrm{~mm}$ light (F8L, white), medium (F8M, gray) and high (F8H, black) toasted oak chips. Different lower case letters indicate significant differences for $p<0.05, n=3$.

ellagitannins were reached in the MWS that were in contact with the light-toasted oak chips. This is in accordance with other studies (Cadahía et al., 2001), which described that toasting implies a decrease in ellagitannin contents. It is also reported that this decrease would contribute to diminish the sensation of bitterness and astringency of wines (Chira \& Tesseidre, 2013).

In the case of the MWS with the smallest chips $(2 \mathrm{~mm})$, higher differences between $\mathrm{L}$ and $\mathrm{M}$ samples in the elagitannin content were observed in the first sampling points than in the last ones. Toasting process provokes not only a decrease in the ellagitannin levels of oak wood, but also important changes in the oak structure (Hale et al., 1999). These changes imply the cracks of the cell walls of the oak wood, making easier the permeation of the hydroalcoholic solution through the wood and the extraction of ellagitannins from the deeper layers of the oak wood. Thus, in the case of the light-toasted oak chips, the ellagitannins from the most superficial layers can be easily extracted making possible to reach high levels of ellagitannin earlier. However, the extraction from the deeper layer is more limited and at the end of the study the ellagitannin evolution rate (oxidation, hydrolysis, etc.) may be faster than the extraction rate. In the case of the medium-toasted oak chips, the extraction from deeper layers could compensate the lower contents from the outermost ones (Jourdes et al., 2011). All this may explain why the differences on the ellagitannin content between the MWS in contact with L chips and those with M chips were reduced at the end of the study. This could not be observed for the MWS containing the high-toasted oak chips since, due to their small size, toasting have probably affected the whole chip and even the ellagitannin from the deepest layers could have been degraded by toasting. As a result, a limited extraction of ellagitannins from these oak chips is achieved and, thereby, the amounts of ellagitannin determined in samples 0F2H were very low during all the study. Thus, the size of oak chips can be crucial depending on the toasting degree, and high temperatures or long times of toasting should not be suitable when the oak chip size is small.

Comparing the samples containing oak chips with the same toasting level and different size, it can be observed that for $\mathrm{L}$ and $\mathrm{M}$ toasting levels, the highest content of ellagitannins was observed for the MWS with the smallest oak chips (Figs. 1 and 3). However, for the toasting level $\mathrm{H}$, the highest concentrations were found in the MWS in contact with the largest oak chips. In this case, due to the higher size of the oak chips, toasting was not as harmful for the deeper layers as it was in the other cases, making then possible the extraction of the ellagitannins from these layers.

The evolution of the ellagitannin content was different depending on the oak chip size. While the total content of 

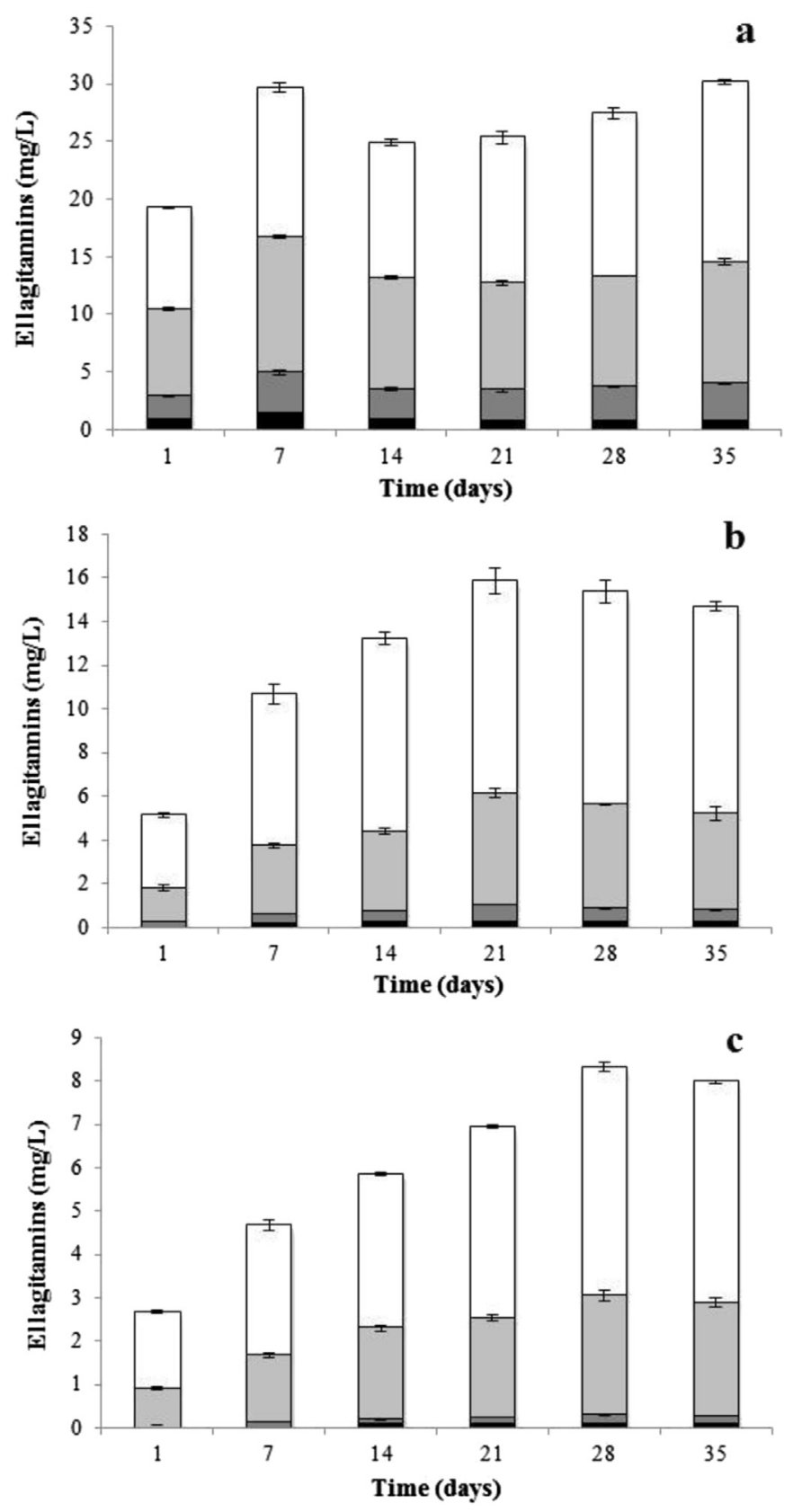

Fig. 4. Quantitative evaluation of individual C-glycosidic ellagitannins castalagin (white), vescalagin (light gray), grandinin (dark gray) and roburin E (black) in model wine solutions in contact with $8 \mathrm{~mm}$ light (a), medium (b) and high (c) toasted oak chips $(n=3)$.

ellagitannins increased regularly during the study in OF2L MWS (Fig. 1), in the 0F8L MWS two maximum contents were observed (Fig. 3). It is possible that for $2 \mathrm{~mm}$ oak chips the hydroalcoholic solution rapidly permeated in the middle of the oak chips so the extraction of the ellagitannins was exhaustive. On the contrary, in the case of the $8 \mathrm{~mm}$ oak chips the extraction of ellagitannins present on the surface occurred during the first 7 days while in the subsequent days, hydroalcoholic solutions deeply infiltrated the primary and the secondary xylem vessels of the wood structure. So another maximum concentration was observed. Therefore, the dimension of oak chips affected the extraction of the ellagitannins: a greater surface-to-volume ratio of chips favored the extraction of C-glycosidic ellagitannins mainly during the first period of contact with the MWS, whereas the extraction from the largest oak chips involved not only the surface layers, but also the deepest ones resulting in more homogeneous ellagitannin levels during all the study.

Regarding the individual composition (Figs. 2 and 4), castalagin seemed to be the most stable ellagitannin since its percentage increased at the end of the study in all the MWS studied, due to a higher rate of disappearance of the other ellagitannins. This is in agreement with other studies pointing out that castalagin is more stable and less reactive than other ellagitannins such as vescalagin (Jourdes, et al., 2009; Quideau et al., 2010). Moreover, the proportions of ellagitannins in the solutions are conditioned by the level of toasting (Table 4). Grandinin and roburin E were the ellagitannins most susceptible to heat treatments respect to other monomeric ellagitannins. Previous studies carried out in our laboratory (data not shown) suggested lower stability of grandinin and roburin $E$ in relation to vescalagin and castalagin, in view of their faster decrease during wine aging. Moreover, the percentages represented by grandinin and roburin E are higher in the MWS in contact with the smallest oak chips than in the corresponding MWS with the highest oak chips, excepting for the high-toasted ones for the reasons explained above. The lower percentages of grandinin and roburin $\mathrm{E}$ in the MWS containing the largest oak chips may be related to a lower extractability of these ellagitannins in relation to castalagin and vescalagin. This has also been observed in previous studies carried out in our laboratory (data not shown) but further studies are necessary to confirm their lower extractability. In addition, the lower surface-to-volume ratio of the $8 \mathrm{~mm}$ oak chips might contribute to the lower extraction of grandinin and roburin $\mathrm{E}$ in the MWS with these chips.

\subsection{Influence of presence of catechin}

The effect of the concentration of (+)-catechin was evaluated on the ellagitannins extraction and on the formation of acutissimin $A$ and B. Although the formation of acutissimin A and acutissimin B was observed (Table 2), the evolution of the vescalagin contents did not show significant differences (data not shown). Only the levels of these ellagitannin derivatives were affected by the $(+)$-catechin concentration, which is explained by the different availability of reagent. It was also observed that toasting degree significantly affected acutissimins $A$ and $B$ concentrations since it affects the ellagitannin contents. The quantity of the two acutissimins was lower in solutions that contained medium-toasted oak chips in relation to those containing light-toasted oak chips, as a consequence of the lower contents of vescalagin (Table 2). In the MWS in contact with light-toasted oak chips and containing $200 \mathrm{mg} / \mathrm{L}$ of (+)-catechin the formation of acutissimins was important at the earlier sampling points whereas in the last sampling points their levels were slightly stabilized, probably as a consequence of a less important formation rate or a higher evolution rate (oxidation, degradation, etc.) at the end of the study. In fact, Petit and coworkers (Petit et al., 2013) have reported that in wine model solution, in presence of oxygen, acutissimins could be converted by oxidation in mongolicains. However, in the MWS with the mediumtoasted chips, the formation of these derivative ellagitannins was more important at the end of the study, in accordance with the evolution of the ellagitannin levels (Figs. 1 and 3). Acutissimin A and B were not detected in MWS containing the high-toasted oak chips except for the set samples containing $200 \mathrm{mg} / \mathrm{L}$ of $(+)$-catechin and $8 \mathrm{~mm}$ oak chips, where the vescalagin content was enough to allow the formation of these derivative ellagitannins at the end of the study. Thus, the toasting level of the oak chips may determine the time when the maximum levels of acutissimins are reached. 
Table 2

Concentration of acutissimin A (mg/L) in model wine solutions containing (+)-catechin during aging with oak chips.

\begin{tabular}{|c|c|c|c|c|c|c|}
\hline Sample & Day $1^{\mathrm{a}}$ & Day $7^{\mathrm{a}}$ & Day 14 & Day 21 & Day 28 & Day 35 \\
\hline $50 \mathrm{~F} 2 \mathrm{~L}$ & $0.172 \pm 0.001 \mathrm{u}, \mathrm{v}, \mathrm{w}, \mathrm{x}$ & $0.46 \pm 0.01 \mathrm{~m}$ & $0.53 \pm 0.011$ & $0.62 \pm 0.01 \mathrm{j}, \mathrm{k}$ & $0.74 \pm 0.02 \mathrm{~g}, \mathrm{~h}$ & $0.82 \pm 0.02 \mathrm{e}, \mathrm{f}$ \\
\hline $50 \mathrm{~F} 2 \mathrm{M}$ & $<$ LOQ & $<\mathrm{LOQ}$ & $0.114 \pm 0.002 x, y$ & $0.19 \pm 0.01 \mathrm{t}, \mathrm{u}, \mathrm{v}, \mathrm{w}$ & $0.266 \pm 0.003 q, \mathrm{r}, \mathrm{s}$ & $0.33 \pm 0.02^{\circ}, \mathrm{p}, \mathrm{q}$ \\
\hline $50 \mathrm{~F} 8 \mathrm{~L}$ & $<$ LOQ & $0.21 \pm 0.01 \mathrm{~s}, \mathrm{t}, \mathrm{u}, \mathrm{v}$ & $0.29 \pm 0.01 \mathrm{p}, \mathrm{q}, \mathrm{r}$ & $0.39 \pm 0.02 m, n, o$ & $0.57 \pm 0.02 \mathrm{k}, \mathrm{l}$ & $0.66 \pm 0.03 i, j$ \\
\hline $50 \mathrm{~F} 8 \mathrm{M}$ & $<$ LOD & $<\mathrm{LOQ}$ & $0.09 \pm 0.03 y$ & $0.14 \pm 0.01 \mathrm{w}, \mathrm{x}, \mathrm{y}$ & $0.16 \pm 0.01 \mathrm{v}, \mathrm{w}, \mathrm{x}, \mathrm{y}$ & $0.190 \pm 0.002 \mathrm{t}, \mathrm{u}, \mathrm{v}, \mathrm{w}$ \\
\hline 200F2L & $0.34 \pm 0.01^{\circ}, \mathrm{p}$ & $0.781 \pm 0.004 \mathrm{f}, \mathrm{g}$ & $0.87 \pm 0.03 e$ & $1.19 \pm 0.06 b$ & $1.25 \pm 0.03 a, b$ & $1.28 \pm 0.05 a$ \\
\hline 200F2M & $<\mathrm{LOQ}$ & $0.18 \pm 0.01 \mathrm{t}, \mathrm{u}, \mathrm{v}, \mathrm{w}, \mathrm{x}$ & $0.23 \pm 0.01 \mathrm{r}, \mathrm{s}, \mathrm{t}, \mathrm{u}$ & $0.36 \pm 0.02 n, 0, p$ & $0.42 \pm 0.02 \mathrm{~m}, \mathrm{n}$ & $0.55 \pm 0.031$ \\
\hline 200F8L & $0.15 \pm 0.01 \mathrm{v}, \mathrm{w}, \mathrm{x}, \mathrm{y}$ & $0.55 \pm 0.02 \mathrm{k}, 1$ & $0.70 \pm 0.02 \mathrm{~h}, \mathrm{i}$ & $1.00 \pm 0.03 d$ & $1.03 \pm 0.04 c, d$ & $1.10 \pm 0.04 c$ \\
\hline 200F8M & $<\mathrm{LOQ}$ & $0.16 \pm 0.01 \mathrm{x}, \mathrm{w}, \mathrm{v}$ & $0.19 \pm 0.01 \mathrm{w}, \mathrm{v}, \mathrm{u}, \mathrm{t}$ & $0.25 \pm 0.01 \mathrm{t}, \mathrm{s}, \mathrm{r}$ & $0.29 \pm 0.01 \mathrm{p}, \mathrm{q}, \mathrm{r}$ & $0.42 \pm 0.02 \mathrm{~m}, \mathrm{n}$ \\
\hline $200 \mathrm{~F} 8 \mathrm{H}$ & $<$ LOQ & $<\mathrm{LOQ}$ & $0.15 \pm 0.00 v, w, x, y$ & $0.21 \pm 0.01 \mathrm{~s}, \mathrm{t}, \mathrm{u}, \mathrm{v}$ & $0.25 \pm 0.01 \mathrm{r}, \mathrm{s}, \mathrm{t}$ & $0.38 \pm 0.01 \mathrm{n}, \mathrm{o}$ \\
\hline
\end{tabular}

Different lower case letters indicate significant differences $(p>0.05, n=3)$.

${ }^{a}$ LOD: Limit of detection. LOQ: limit of quantification.

Table 3

Concentration of acutissimin B (mg/L) in model wine solutions containing $(+)$-catechin during aging with oak chips.

\begin{tabular}{|c|c|c|c|c|c|c|}
\hline \multirow[t]{2}{*}{ Sample } & \multicolumn{6}{|c|}{ Concentration of acutissimin B $(\mathrm{mg} / \mathrm{L})^{\mathrm{a}}$} \\
\hline & Day 1 & Day 7 & Day 14 & Day 21 & Day 28 & Day 35 \\
\hline 50F2L & $<\mathrm{LOQ}$ & $0.133 \pm 0.004 c, d$ & $0.16 \pm 0.01 \mathrm{e}, \mathrm{f}, \mathrm{g}, \mathrm{h}$ & $0.19 \pm 0.01 \mathrm{i}, \mathrm{j}, \mathrm{k}, \mathrm{l}$ & $0.22 \pm 0.01 \mathrm{n}, \mathrm{o}$ & $0.227 \pm 0.003 n, 0$ \\
\hline 50F2M & $<$ LOQ & $<\mathrm{LOQ}$ & $<$ LOQ & $<\mathrm{LOQ}$ & $0.111 \pm 0.004 a, b, c$ & $0.13 \pm 0.01 c, d$ \\
\hline 50F8L & $<$ LOD & $<\mathrm{LOQ}$ & $0.12 \pm 0.01 b, c$ & $0.15 \pm 0.01 \mathrm{~d}, \mathrm{e}, \mathrm{f}, \mathrm{g}$ & $0.18 \pm 0.04 \mathrm{~h}, \mathrm{i}, \mathrm{j}, \mathrm{k}$ & $0.219 \pm 0.002 \mathrm{~m}, \mathrm{n}$ \\
\hline $50 F 8 M$ & $<$ LOQ & $<\mathrm{LOQ}$ & $<\mathrm{LOQ}$ & $<$ LOQ & $<\mathrm{LOQ}$ & $<$ LOQ \\
\hline 200F2L & $0.129 \pm 0.002 c, d$ & $0.22 \pm 0.01 \mathrm{n}, 0$ & $0.264 \pm 0.002 p$ & $0.28 \pm 0.02 p$ & $0.324 \pm 0.007 q$ & $0.28 \pm 0.01 p$ \\
\hline 200F2M & $<\mathrm{LOQ}$ & $<\mathrm{LOQ}$ & $0.101 \pm 0.005 a, b$ & $0.131 \pm 0.004 c, d$ & $0.19 \pm 0.01 \mathrm{j}, \mathrm{k}, \mathrm{l}, \mathrm{m}$ & $0.238 \pm 0.008 n, 0$ \\
\hline 200F8L & $<$ LOQ & $0.17 \pm 0.01 \mathrm{~g}, \mathrm{~h}, \mathrm{i}, \mathrm{j}$ & $0.21 \pm 0.01 \mathrm{k}, \mathrm{l}, \mathrm{m}, \mathrm{n}$ & $0.21 \pm 0.01 \mathrm{k}, \mathrm{l}, \mathrm{m}, \mathrm{n}$ & $0.24 \pm 0.01 \mathrm{o}$ & $0.224 \pm 0.007 n, 0$ \\
\hline $200 \mathrm{~F} 8 \mathrm{M}$ & $<$ LOD & $<\mathrm{LOQ}$ & $0.09 \pm 0.01 a$ & $0.12 \pm 0.01 b, c$ & $0.15 \pm 0.01 \mathrm{~d}, \mathrm{e}, \mathrm{f}$ & $0.17 \pm 0.01 \mathrm{f}, \mathrm{g}, \mathrm{h}, \mathrm{i}$ \\
\hline $200 \mathrm{~F} 8 \mathrm{H}$ & $<$ LOD & $<$ LOQ & $<$ LOQ & $0.09 \pm 0.01 \mathrm{a}, \mathrm{b}$ & $0.115 \pm 0.005 b, c$ & $0.135 \pm 0.004 b, c, d$ \\
\hline
\end{tabular}

Different lower case letters indicate significant differences $(p>0.05, n=3)$.

a LOD: Limit of detection. LOQ: Limit of quantification.

Table 4

Percentage $(\mathrm{x} \pm \mathrm{SD})$ represented by each ellagitannin during all the study.

\begin{tabular}{lllll}
\hline \multirow{2}{*}{ Sample } & \multicolumn{4}{l}{ Percentage on the total ellagitannin content $(\%)^{\mathrm{a}}$} \\
\cline { 2 - 5 } & Grandinin & Vescalagin & Roburin $\mathrm{E}$ & Castalagin \\
\hline OF2L & $17.5 \pm 0.9 \mathrm{a}$ & $32 \pm 5 \mathrm{a}, \mathrm{b}$ & $7 \pm 1 \mathrm{a}$ & $44 \pm 4 \mathrm{a}$ \\
OF2M & $5.1 \pm 0.2 \mathrm{~b}$ & $37 \pm 3 \mathrm{c}$ & $2.3 \pm 0.3 \mathrm{~b}$ & $55 \pm 2 \mathrm{~b}$ \\
OF2H & $<$ LOQ $^{\mathrm{b}}$ & $32 \pm 5 \mathrm{a}, \mathrm{b}$ & $1.1 \pm 0.1 \mathrm{c}$ & $69 \pm 4 \mathrm{c}$ \\
OF8L & $10.8 \pm 0.8 \mathrm{c}$ & $37 \pm 2 \mathrm{c}$ & $3.6 \pm 0.9 \mathrm{~d}$ & $48 \pm 3 \mathrm{~d}$ \\
OF8M & $3.9 \pm 0.5 \mathrm{~d}$ & $30 \pm 2 \mathrm{a}$ & $1.7 \pm 0.2 \mathrm{~b}, \mathrm{c}$ & $65 \pm 2 \mathrm{e}$ \\
OF8H & $2.0 \pm 0.4 \mathrm{e}$ & $33 \pm 2 \mathrm{~b}$ & $1.2 \pm 0.1 \mathrm{c}$ & $64 \pm 2 \mathrm{e}$ \\
\hline
\end{tabular}

a Different lower case letters within each column indicates significant differences $(p<0.05 ; n=18)$.

b LOQ: Limit of quantification.

The oak chip size also affected the levels of acutissimins, since it affects the ellagitannin concentration in the media. For the same concentration of $(+)$-catechin the highest levels of acutissimins were always determined in the MWS in contact with the smallest chips. This can be explained by the higher levels of vescalagin in these MWS (Figs. 2 and 4).

The amounts of acutissimin A were much higher than the amounts of acutissimin $B$ in accordance with the reactivity described for vescalagin and (+)-catechin (Quideau et al., 2005). Furthermore, the formation of the A-isomer was faster than that of the B-isomer, since the former could be detected and quantified at earlier sampling points.

\section{Conclusions}

The effect of the toasting degree and size of $Q$. petraea oak chips on the levels of the individual ellagitannins in model wine solutions has been evaluated in this work for the first time. The toasting degree of the oak chips significantly affected not only the qualitative composition and levels of total ellagitannins but also the time when the maximum concentration is reached: the levels of ellagitannins were higher and reached earlier in the set of samples in contact with light-toasted oak chips and grandinin and roburin $\mathrm{E}$ are the ellagitannins most susceptible to heat treatments.

The highest amounts of ellagitannins were found in the set of samples containing the smallest oak chips, due to the greater surface-to-volume ratio. However, high-toasting levels can affect the whole chip if its size is too small degrading most of the ellagitannins. Moreover, the size also affected the evolution of the ellagitannin contents and in the case of the largest oak chips with a light level of toasting a second maximum in the levels of ellagitannins could be observed as a consequence of the extraction of the ellagitannis from the deeper layers of the oak chip. Hence, taking into account the size and the toasting degree of the oak chips the levels and evolution of ellagitannin content could be modulated and it seemed that high temperatures or long times of toasting should not be used when the oak chip size is small.

The concentration of $(+)$-catechin did not significantly affect the total concentration of ellagitannins in the solutions. The formation of acutissimins A and B depends on the levels of $(+)$-catechin and ellagitannins. Since these latter are affected both by the toasting degree and by the size of oak chips, these two parameters affect the formation of acutissimins which is more important in the solutions in contact with small and light-toasted oak chips.

\section{Acknowledgments}

The authors thank AEB Group (Brescia, Italy) for chip samples. I. García-Estévez thanks the Spanish "Ministerio de Educación, Cultura y Deporte" for the F.P.U. predoctoral scholarship. 


\section{References}

Cadahía, E., Varea, S., Muñoz, L., Fernández de Simón, B., \& García -Vallejo, M. C. (2001). Evolution of ellagitannins in Spanish, French, and American oak woods during natural seasoning and toasting. Journal of Agricultural and Food Chemistry, 49, 3677-3684.

Chassaing, S., Lefeuvre, D., Jacquet, R., Jourdes, M., Ducasse, L., Galland, S., et al (2010). Physicochemical studies of new anthocyano-ellagitannin hybrid pigments: about the origin of the influence of oak C-glycosidic ellagitannins on wine color. European Journal of Organic Chemistry, 2010, 55-63.

Chira, K., \& Teissedre, P. L. (2013). Extraction of oak volatiles and ellagitannins compounds and sensory profile of wine aged with French winewoods subjected to different toasting methods: behaviour during storage. Food Chemistry, 140, $168-177$.

Commission Regulation (EC) No 1507/2006 of 11 October 2006 amending Regulations (EC) No 884/2001 and (EC) No 753/2002 concerning certain detailed rules implementing Regulation (EC) No 1493/1999 on the common organization of the market in wine, as regards the use of pieces of oak wood in winemaking and the designation and presentation of wine so treated.

Commission Regulation Council Regulation (EC) No 2165/2005 of 20 December 2005 amending Regulation (EC) No 1493/1999 on the common organization of the market in wine.

Doussot, F., De Jesso, B., Quideau, S., \& Pardon, P. (2002). Extractives content in cooperage oak wood during natural seasoning and toasting: influence of tree species, geographic location, and single-tree effects. Journal of Agricultural and Food Chemistry, 50, 5955-5961.

Fernández de Simón, B., Cadahía, E., Del Álamo, M., \& Nevares, I. (2010). Effect of size, seasoning and toasting in the volatile compounds in toasted oak wood and in a red wine treated with them. Analytica Chimica Acta, 660, $211-220$.

Fernández de Simón, B., Hernández, T., Cadahía, E., Dueñas, M., \& Estrella, I. (2003). Phenolic compounds in a Spanish red wine aged in barrels made of Spanish, French and American oak wood. European Food Research and Technology, 216, $150-156$.

Fernández de Simón, B., Sanz, M., Cadahía, E., Poveda, P., \& Broto, M. (2006). Chemical characterization of oak heartwood from Spanish forests of Quercus pyrenaica (Wild). Ellagitannins, low molecular weight phenolic, and volatile compounds. Journal of Agricultural and Food Chemistry, 54, 8314-8321.

Francia-Aricha, E. M., Guerra, M. T., Rivas-Gonzalo, J. C., \& Santos-Buelga, C. (1997), New anthocyanin pigments formed after condensation with flavanols. Journal of Agricultural and Food Chemistry, 45, 2262-2266.

García-Estevéz, I., Escribano-Bailón, M. T., Rivas-Gonzalo, J. C., \& Alcade-Eon, C. (2010). Development of a fractionation method for the detection and identification of oak ellagitannins in red wines. Analytical Chimica Acta, 669, $171-176$.
García-Estevéz, I., Escribano-Bailón, M. T., Rivas-Gonzalo, J. C., \& Alcade-Eon, C. (2012). Validation of a mass spectrometry method to quantify oak ellagitannins in wine samples. Journal of Agricultural and Food Chemistry, 60, 1373-1379.

Glabasnia, A., \& Hofmann, T. (2006). Sensory-directed identification of taste-active ellagitannins in American (Quercus alba L.) and European oak wood (Quercus robur L.) and quantitative analysis in Bourbon whiskey and oak-matured red wines. Journal of Agricultural and Food Chemistry, 54, 3380-3390.

Hale, M. D., McCafferty, K., Larmie, E., Newton, J., \& Swan, J. S. (1999). The influence of oak seasoning and toasting parameters on the composition and quality of wine. American Journal of Enology and Viticulture, 50, 495-502.

Hervé du Penhoat, C., Michon, V., Peng, S. Y., Viriot, C., Scalbert, A., \& Gage, D. (1991) Structural elucidation of new dimeric ellagitannins from Quercus robur L. Roburin A-Roburin E. Journal of the Chemical Society-Perkin Transactions, 1(1), 1653-1660.

Jourdes, M., Lefeuvre, D., \& Quideau, S. (2009). C-Glycosidic ellagitannins and their influence on wine chemistry. In S. Quideau (Ed.), Chemistry and biology of ellagitannins - An underestimated class of bioactive plants polyphenols ( $\mathrm{pp}$. 320-374). Singapore: Imperial College Press/Word Scientific.

Jourdes, M., Michel, J., Saucier, C., Quideau, S., \& Teissedre, P. L. (2011). Identification, amounts and kinetics of extraction of C-glucosidic ellagitannins during wine aging in oak barrels or in stainless steel tanks with oak chips. Analytical and Bioanalytical Chemistry, 500, 1531-1539.

Masson, G., Moutounet, M., \& Puech, J. L. (1995). Ellagitannin content of oak wood as function of species and of sampling position in the tree. American Journal of Enology and Viticulture, 46, 262-268.

Petit, E., Lefeuvre, D., Jacquet, R., Pouységu, L., Deffieux, D., \& Quideau, S. (2013). Remarkable biomimetic chemoselective aerobic oxidation of flavanoellagitannins found in oak-aged wine. Angewandte Chemie International Edition, 52, 11530-11533.

Puech, J. L., Feuillat, F., \& Mosedale, J. R. (1999). The tannins of oak heartwood: structure, properties, and their influence on wine flavor. American Journal of Enology and Viticulture, 50, 469-478.

Quideau, S., Jourdes, M., Lefeuvre, D., Montaudon, D., Saucier, C., Glories, Y., et al (2005). The chemistry of wine polyphenolic C-glycosidic ellagitannins targeting human topoisomerase II. Chemistry - European Journal, 11, 6503-6513.

Quideau, S., Jourdes, M., Lefeuvre, D., Pardon, P., Saucier, C., Teissedre, P. L., et al. (2010). Ellagitannins - an underestimated class of bioactive plants polyphenols: chemical reactivity of C-glucosidic ellagitannins in relation to wine chemistry and biological activity. In C. Santos-Buelga, M. T. Escribano-Bailón, \& V. Lattanzio (Eds.), Recent advances in polyphenols research (Vol. 2, pp. 81-137). Singapore: Blackwell Publishing Ltd.

Timberlake, C. F., \& Bridle, P. (1976). Interactions between anthocyanins, phenolic compounds, and acetalheyde and their significance in red wines. American Journal of Enology and Viticulture, 27, 97-105.

Vivas, N., \& Glories, Y. (1996). Role of oak wood ellagitannins in the oxidation process of red wines during aging. American Journal of Enology and Viticulture, 47, 103-107. 